NISTIR 7013

\title{
The Global Combustion Behavior of 1 MW to 3 MW Hydrocarbon Spray Fires Burning in an Open Environment
}

\author{
Anthony Hamins \\ Alexander Maranghides \\ George Mulholland
}


NISTIR 7013

\title{
The Global Combustion Behavior of 1 MW to 3 MW Hydrocarbon Spray Fires Burning in an Open Environment
}

\author{
Anthony Hamins \\ Alexander Maranghides \\ George Mulholland \\ Building and Fire Research Laboratory
}

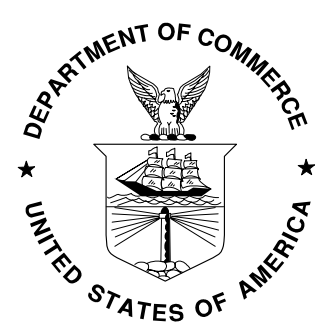

\section{U.S. DEPARTMENT OF COMMERCE}

Donald L. Evans, Secretary TECHNOLOGY ADMINISTRATION

Phillip J. Bond, Under Secretary of Commerce for Technology NATIONAL INSTITUTE OF STANDARDS AND TECHNOLOGY

Hratch G. Semerjian, Acting Director 


\begin{abstract}
A series of experiments were conducted in order to determine the global combustion behavior of a number of liquid fuels burning in large (1 MW to $3 \mathrm{MW}$ ) spray fires in an open environment. The experiments described here provide a characterization of the global fire characteristic of the liquid spray burner, which is a standard fixture in the NIST Large Fire Laboratory. The fuels tested include n-heptane, toluene, a commercial blend of heptane isomers, Jet A, and a heptane/toluene fuel mixture. The fuel flow was controlled. Measurements were made of the radiative emission to the surroundings, the heat release rate, and the emission of soot, $\mathrm{CO}_{2}$, and $\mathrm{CO}$. These measurements were normalized by the mass burning rate to determine the radiative heat loss fraction, the combustion efficiency, and the yields of soot, $\mathrm{CO}_{2}$, and $\mathrm{CO}$.
\end{abstract}

\title{
1. Introduction
}

Global fire properties are needed as input for CFD fire models. Although there is some information available in the literature regarding the global combustion behavior of hydrocarbon pool fires, there is little data on large ( $>1 \mathrm{MW})$ fires, and almost nothing on large spray fires.

A series of experiments were conducted in order to determine the global combustion behavior of a number of liquid fuels burning in a spray flame in an open environment. Measurements were made of the radiative emission to the surroundings, the heat release rate and the yields of soot, $\mathrm{CO}_{2}$, and $\mathrm{CO}$. Through control of the fuel mass burning rate and measurement of the heat release rate, the combustion efficiency was determined. The mass burning rate information and measurement of the emitted radiation allowed determination of the fractional radiative heat loss. The soot yield was determined from knowledge of the mass burning rate $(\dot{m})$ and through extractive sampling and subsequent analysis of the mass of soot relative to $\mathrm{CO}$ and $\mathrm{CO}_{2}$ in the fire plume.

The experiments described here provide a characterization of fires in the liquid spray burner, which is a standard fixture in the Large Fire Laboratory, for heat release rates between $1 \mathrm{MW}$ and $3 \mathrm{MW}$. The burner has been used in a number of large fire experiments including the International Fire Model Benchmarking and Validation Exercise sponsored by the Nuclear Regulatory Commission [Hamins et al., 2003]. The fuels selected here include the fuels used in those experiments.

This report is organized into three Sections. In the remainder of Section 1, the definitions of combustion efficiency and radiative fraction are provided. In Section 2, the experimental apparatus, procedures, and measurement uncertainty are described. The measurement results are discussed in Section 3. Each Section addresses the measurements of interest including the heat release rate, the radiative fraction, and the yields of soot, $\mathrm{CO}$, and $\mathrm{CO}_{2}$. 


\subsection{Definitions}

The radiative heat loss fraction from a fire $\left(\chi_{\mathrm{r}}\right)$ is defined as the ratio of the rate of radiative energy emitted to the surroundings $\left(\dot{Q}_{r}\right)$ to the idealized heat release rate $\left(\dot{m} \cdot \mathrm{H}_{\mathrm{c}}\right)$ :

$$
\chi_{\mathrm{r}}=\dot{Q}_{r} /\left(\dot{m} \cdot \mathrm{H}_{\mathrm{c}}\right)
$$

where $\mathrm{H}_{\mathrm{c}}$ is the net heat of combustion of the fuel (in units of $\mathrm{MJ} / \mathrm{kg}$ ). In the spray burner, unlike a pool fire, the value of $\dot{m}$ was controlled such that it was a constant value during the tests.

The heat release rate of a fire is a critical experimental parameter. The heat release rate represents the amount of energy per unit time that is generated by the fire. It is the value of the heat release rate that controls the thermal environment and drives the radiative and convective heat transfer, the fluid flow, the thermal insult onto secondary items such as structural members, the rate of fire spread and growth, the volume of smoke and toxic products, and ultimately the hazard associated with a fire. The heat release rate $(\dot{Q})$ is the product of the mass burning rate of the fuel $(\dot{m})$, the heat of combustion of the fuel $\left(\mathrm{H}_{\mathrm{c}}\right)$ and the combustion efficiency $\left(\chi_{a}\right)$.

$$
\dot{Q}=\chi_{\mathrm{a}} \cdot \dot{m} \cdot \mathrm{H}_{\mathrm{c}}
$$

The combustion efficiency was determined by measuring $\dot{Q}$, controlling $\dot{m}$, and knowledge of the value of $\mathrm{H}_{c}$. The combustion efficiency is known to vary for different fuels, and is limited by definition to values between 0 and 1 .

\subsection{Fuel Properties}

The fuels tested included n-heptane, toluene, heptane, Jet A, and a heptane/toluene fuel mixture. Toluene, heptanes, and Jet A are commercially available fuels. Heptane is a blend of heptane isomers. The value of $\mathrm{H}_{\mathrm{c}}$ was known or was determined for each of the fuels. Table 1 lists the value of $\mathrm{H}_{\mathrm{c}}$ as well as other properties required to characterize the fuels, including the liquid density at ambient temperature and the value of the heat of combustion per unit mass of oxygen consumed $\left(\mathrm{H}_{\mathrm{c}} / \mathrm{r}_{\mathrm{o}}\right)$, where $\mathrm{r}_{\mathrm{o}}$ is the mass of oxygen consumed per unit mass of fuel. The parameter $\left(\mathrm{H}_{\mathrm{c}} / \mathrm{r}_{\mathrm{o}}\right)$ is an important parameter used in calorimetry [Bryant et al., 2003].

\section{Experimental Apparatus and Procedure}

The fuel system was designed to deliver a uniform liquid fuel flow. The system consisted of a fuel storage container and a magnetic drive positive displacement gear pump. The pump was controlled by a variable frequency driver. Fuel was delivered through two atomizing spray nozzles oriented down onto a $1 \mathrm{~m}$ by $2 \mathrm{~m}$ stainless steel pan. The spray nozzles were located about $0.6 \mathrm{~m}$ above the pan. The pan was $7 \mathrm{~cm}$ deep. The nozzles had a $90^{\circ}$ spray angle. A plan view of the experiments is shown in Fig. 1. The fuel flow was calibrated with a graduated cylinder and stopwatch.

Measurements were made for at least 2 min after the fire had reached steady state burning. The fuel mass burning rate was controlled. Because of this, steady burning 
required much less time to achieve than for a typical pool fire, taking as little as $1 / 2 \mathrm{~min}$ as determined from the measurements of the radiative flux from the fire.

Since all of the measurements results are normalized by the fuel mass burning rate $(\dot{m})$, uncertainty its measurement is a major factor in an analysis of the uncertainty in the determination of the fire radiative fraction and combustion efficiency. The value of $\dot{m}$ was determined at least three times before and three times after each experiment. The average value of the standard deviation was equal to $1 \%$, with its value ranging from 0.1 $\%$ to $2.4 \%$.

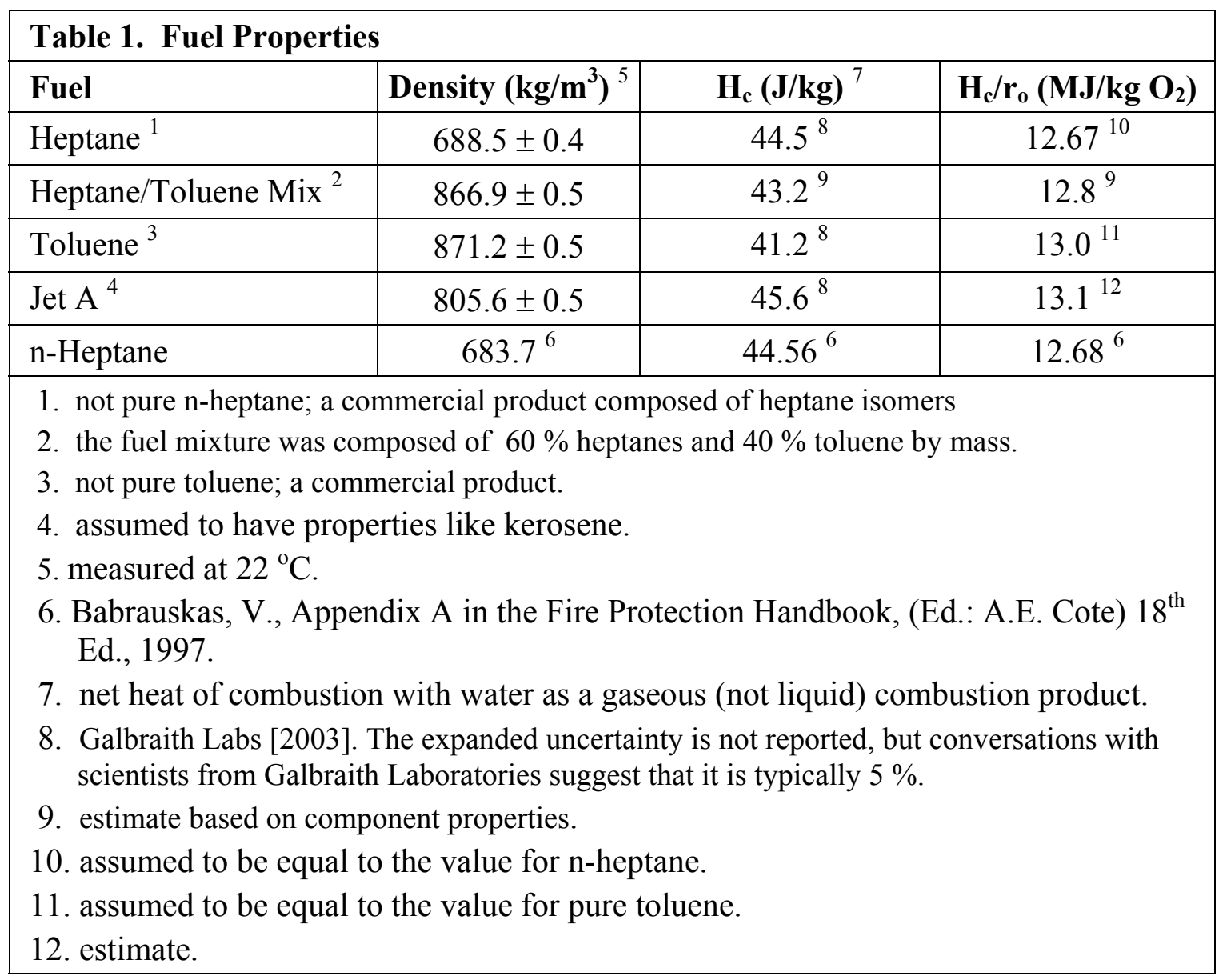

\subsection{Radiative Heat Flux to the Surroundings}

The radiative heat flux $\left(\dot{q}^{\prime}\right)$ was measured using calibrated Gardon total heat flux sensors positioned at a distance of $6 \mathrm{~m}$ to $14 \mathrm{~m}$ from the center of the fire pan and positioned $2 \mathrm{~m}$ above the burner, which was approximately $1 / 2$ of that expected for the time-averaged fire height. Measurements were made for at least $2 \mathrm{~min}$ at a sampling rate of $10 \mathrm{~Hz}$, which was saved as a running $1 \mathrm{~s}$ average. Instrument time response was approximately $1 / 2 \mathrm{~s}$. Background signal was taken before and after every measurement. The gauges had a 
$150^{\circ}$ view angle. The sensor surface was sprayed with a high emissivity $(=0.95)$ paint that was spectrally flat.

It was assumed that the fire was symmetric about every quadrant around the pan center. Measurements were simultaneously made at several angles $\left(\theta=0^{\circ}, 30^{\circ}, 60^{\circ}, 90^{\circ}\right.$ in Fig. 1), using several gauges to determine the dependence of flux with angle. At one location, three gauges were positioned in very close proximity to facilitate the uncertainty analysis. The value of the total radiative flux emitted by the fire $\left(\dot{Q}_{r}\right)$ was determined assuming that the spray fire was symmetric about the center of the rectangular pan:

$$
\dot{Q}_{r}=8 \mathrm{R}^{2} \int_{0}^{\pi / 2} \dot{q}^{\prime \prime}(\theta) \mathrm{d} \theta
$$

where $\mathrm{R}$ is the distance between the center of the fire pan, and $\dot{q}^{\prime \prime}$ is the measured radiative heat flux as a function of angle, $\theta$ (see Fig. 1).

The value of $\chi_{\mathrm{r}}$ was determined using the measured results for $\dot{q}$ " and $\dot{m}$ in conjunction with Eqs. 1 and 3. The assumption of point source radiative emission has been found to be an acceptable approximation for pool fires, providing that the distance between the heat flux gauge and the fire is greater than five times the fuel pan radii [Modak, 1976; 1977]. The point source assumption was tested at a number of angles by comparing the product of $\dot{q}^{\prime \prime}$ and $\mathrm{R}^{2}$ determined from gauges at various values of $\mathrm{R}$ for a particular value of $\theta$. The flux measurements were integrated about the pan and the value of $\dot{Q}_{r}$ in Eq. 3 was determined. The value of $\chi_{\mathrm{r}}$ was then determined using Eq. 1 and the mass burning rate data.

\subsection{Heat Release Rate}

The fire heat release rate $(\dot{Q})$ was measured using oxygen consumption calorimetry in the standard manner through measurement of exhaust products in the $6 \mathrm{~m}$ by $6 \mathrm{~m}$ hood [Bryant et al. 2003; 2004]. The exhaust products from the compartment flowed into the 6 $\mathrm{m}$ exhaust duct where the gas flow was characterized. This form of fire calorimetry is based on the fact that the oxygen deficit in the exhaust duct flow (relative to ambient air) is a measure of the heat release rate of a fire. The calorimeter measurement system in the $6 \mathrm{~m}$ hood measures the velocity, temperature, and concentrations of oxygen, $\mathrm{CO}$, and $\mathrm{CO}_{2}$. This data was used to determine the heat release rate. A correction is made for ambient humidity. This system was calibrated before each test using carefully measured flows of natural gas, with fires as large as $2 \mathrm{MW}$. A detailed analysis of the combined expanded uncertainty in the $\dot{Q}$ measurement yields a value of approximately $11 \%$ for fires in the $\dot{Q}=1 \mathrm{MW}$ range [Bryant, 2003]. Further details can be found in Bryant et al. [2003; 2004], which includes a thorough description of the experimental methodology, hardware, instrumentation, procedures, and uncertainty. 


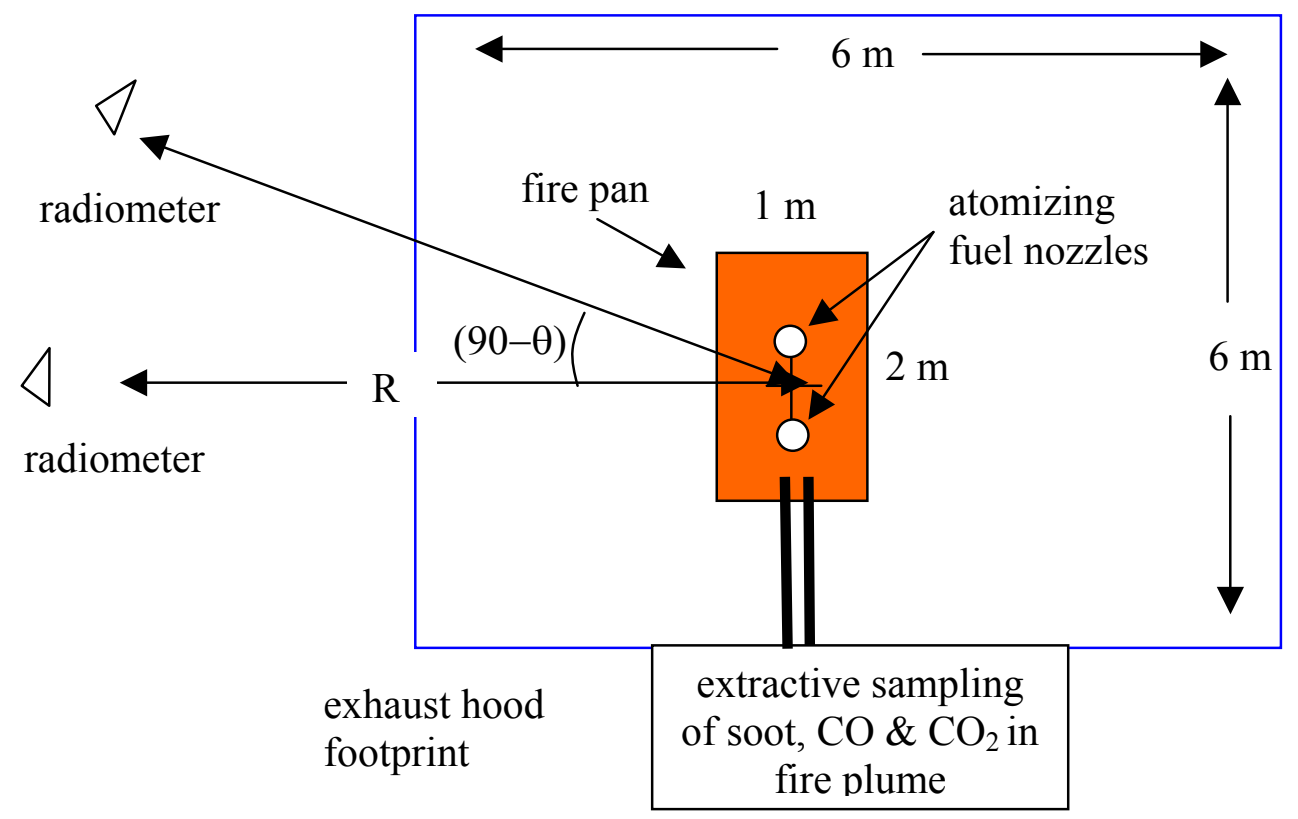

Figure 1. Plan view of experiments designed to determine global combustion parameters for a number of liquid fuels. Radiative flux measurements were made for several values of $\theta$ and $R$, while gas samples were extracted above the fire plume.

\subsection{Soot, $\mathrm{CO}$ and $\mathrm{CO}_{2}$ Yields}

The yields of soot, $\mathrm{CO}$ and $\mathrm{CO}_{2}$ were measured just above the visible fire, in the plume. The yield is defined as the number of grams of a compound emitted per gram of fuel burnt. The soot yield was determined by using the carbon balance method applied to measurements of soot, $\mathrm{CO}$, and $\mathrm{CO}_{2}$.

Two collection probes were positioned over the center of the burner at a height of $4.15 \mathrm{~m}$ above the pan (see Fig.1). The probes were mounted parallel to each other and were separated by $23 \mathrm{~cm}$. Each probe has a nominal $1 \mathrm{~mm}$ bead size thermocouple near the sampling point of the probe. Qualitatively, the plume seemed to angle slightly toward the north wall and the Probe 1 TC reading was almost always higher than the Probe 2 reading.

The tests consisted of turning on the burner, achieving steady state conditions, sampling from the filter attached to Probe 1 for a period of time, and then at a later time sampling with the filter attached to Probe 2. Initially, an ambient bypass flow was introduced just downstream of the filter that flows through the gas analyzers. Then, the by-pass solenoid is closed and the Probe 1 solenoid is opened. At the completion of collecting the first sample, the Probe 1 solenoid is closed and the bypass is opened to allow the gases in the long sampling line to be measured by the gas analyzers. The second filter sample is collected after the gas analyzers have reached their background value, and the burner is at steady state at a second $\dot{Q}$. 
The sampling time for the thermocouple and the $\dot{Q}$ measurement, and the approximate time interval for the smoke collection were $2 \mathrm{~min}$. The burner was nominally steady when the measurement began. A mass flow controller was used to maintain a constant rate of sample extraction from the plume. The flow was sampled at $5.00 \mathrm{~cm}^{3} / \mathrm{s}(3.00$ $\mathrm{L} / \mathrm{min}$ ) at $1 \mathrm{~atm}$ pressure and $21^{\circ} \mathrm{C}$. The smoke entered the $3.6 \mathrm{~m}$ long stainless steel probe at the plume temperature in the range $100{ }^{\circ} \mathrm{C}$ to $200{ }^{\circ} \mathrm{C}$. A water-jacket heat exchanger surrounded the last $60 \mathrm{~cm}$ of the sampling line to control the temperature of the smoke entering the filter at near $60{ }^{\circ} \mathrm{C}$. This prevented condensation of moisture on the filter.

The smoke yield was determined by the carbon balance method. This method required a determination of the ratio of the smoke mass in a given volume to the total mass of carbon in the form of gas or particulate in the same volume. This was accomplished by dividing the smoke mass collected on a filter by the sum of the smoke mass and the mass of carbon contained in the forms of $\mathrm{CO}$ and $\mathrm{CO}_{2}$. Laboratory scale studies with ethene indicate that for free burning conditions the contributions of unburned vapor phase hydrocarbons account for about $2 \%$ or less of the carbon [Leonard et al., 1994]. The unburned hydrocarbons are neglected in this analysis, but are included in the uncertainty analysis. The equation for calculating the smoke yield $\left(y_{s}\right)$ in terms of the $\mathrm{CO}_{2}$ and $\mathrm{CO}$ concentrations is given by:

$$
y_{s}=\frac{f m_{s}}{\left[m_{s}+12 n_{t}\left(\Delta \varphi\left(C O_{2}\right)+\Delta \varphi(C O)\right]\right.} \text {. }
$$

The quantity $f$ is the carbon mass fraction of the fuel, $m_{\mathrm{s}}$ is the mass of the smoke sample collected on a filter and on the wall of the sampling probe, $n_{t}$ is the number of moles of gas sampled, and the constant 12 represents the molar mass of carbon in grams. The quantities $\Delta \varphi(\mathrm{CO})$ and $\Delta \varphi\left(\mathrm{CO}_{2}\right)$ are the volume fractions of $\mathrm{CO}$ and $\mathrm{CO}_{2}$ of the gas sample taken during the test minus the ambient background volume fractions of these gases. The yield for $\mathrm{CO}$ is given by a similar formula:

$$
y_{C O}=\frac{f n_{t} 28(\Delta \varphi(C O)}{\left[m_{s}+12 n_{t}\left(\Delta \varphi\left(C O_{2}\right)+\Delta \varphi(C O)\right]\right.}
$$

where 28 is the molecular weight of $\mathrm{CO}$. For n-heptane and the heptane blend, the $\mathrm{CO}$ concentration was not measurable above the background. In these cases we estimate that the $\mathrm{CO}$ yield is less than $8 \times 10^{-3}$ based on a minimum detectable $\mathrm{CO}$ volume fraction of $2 \times 10^{-5}$.

The measured mass concentrations of soot correspond to the values at the sample location and the corresponding temperature. The value is computed using the following formula:

$$
M_{s}=\frac{m_{f}+C_{c} m_{c}}{V\left(T_{\text {smoke }}\right)},
$$

where $m_{f}$ is the mass of smoke collected on the filter, $m_{c}$ the mass collected on the walls of the sampling tube, $C$ a correction factor based on the amount not removed by the first wiping of the cloth, and $V$ is the volume of smoke sampled at temperature $T_{\text {smoke. The }}$ concentration in the flame itself will be greater. The volume fraction of soot is obtained 
by dividing the mass concentration by the density of soot, which is taken to be $1.8 \mathrm{~g} / \mathrm{cm}^{3}$. This represents the volume of the condensed phase soot per volume of gas at the sampling point. This value can be expected to be higher in the flame.

The volume of gas sampled at the probe inlet was somewhat greater than $3 \mathrm{~L} / \mathrm{min}$, because the gas temperature at the sampling point was greater than $21{ }^{\circ} \mathrm{C}$. The ideal gas equation was used to compute the volume sampled with the measured temperature. For Probe 1 , the temperature used in the calculation of the volume was $231{ }^{\circ} \mathrm{C}$ (averaged over the first filter collection), while for Probe 2 the temperature used was $126^{\circ} \mathrm{C}$.

\section{Uncertainty Analysis for Soot, $\mathrm{CO}_{2}$, and $\mathrm{CO}$ yields}

The estimated standard uncertainty in the volume fraction of the measured $\mathrm{CO}_{2}$ and $\mathrm{CO}$, $\mathrm{u}_{\mathrm{I}}\left(\mathrm{CO}_{2}\right)$ and $\mathrm{u}_{\mathrm{I}}(\mathrm{CO})$ are $15 \times 10^{-5}$ and $3 \times 10^{-5}$. These estimates are based on using two sets of span gases (span 1volume fractions: 0.180 for $\mathrm{CO}_{2}, 0.0700$ for $\mathrm{CO}$; span 2 volume fractions: 0.0151 for $\mathrm{CO}_{2}, 0.000152$ for $\mathrm{CO}$ ) and analysis of the instrument noise and drift. These estimates were more than an order of magnitude lower than the nominal gas analyzer uncertainty.

The law of propagation of uncertainty was used to compute the total uncertainty in the smoke yield arising from the quantities appearing in Eq. 4. As indicated in Table 2 below, the dominant sources of uncertainty are the smoke mass, the mole fraction of $\mathrm{CO}_{2}$, and the molar gas flow. The resulting relative total standard uncertainty was 0.064 . To compute the relative combined standard uncertainty of the mean, the total uncertainty is combined in quadrature with the relative standard uncertainty of the mean of the repeat measurements. Finally, the expanded uncertainty was computed using a coverage factor of two. The results are presented in Table 4.

The major terms contributing to the uncertainty in the $\mathrm{CO}$ yield are the uncertainty in the $\mathrm{CO}$ volume fraction, which affects the numerator of $\mathrm{Eq}(5)$, and the volume fraction of $\mathrm{CO}_{2}$, which is the dominant term in the denominator. The relative total standard uncertainty in the $\mathrm{CO}$ yield, $\mathrm{u}_{\mathrm{t}}\left(\mathrm{y}_{\mathrm{CO}}\right)$, is equal to the root-sum-square of the relative standard uncertainties for $\mathrm{CO}$ and $\mathrm{CO}_{2}$ measurements.

$$
u_{t}\left(y_{C O}\right)=\left(u_{1 r}^{2}(C O)+u_{1 r}^{2}\left(C O_{2}\right)\right)^{1 / 2}
$$

The relative uncertainty $\mathrm{u}_{1 \mathrm{r}}=\mathrm{u}_{\mathrm{I}} / \varphi$, where $\varphi$ is the volume fraction of the gas. From this result, the expanded uncertainty was computed using the same general approach as above. The results are given in Table 4 .

The uncertainty in the yield of $\mathrm{CO}_{2}$ was small, because the numerator and denominator of the yield equation were dominated by the volume fraction of $\mathrm{CO}_{2}$. The largest uncertainty was for toluene, for which the ratio of the mass of soot to the mass of carbon in the generated $\mathrm{CO}_{2}$ is approximately 0.25 . For $\mathrm{CO}$, the ratio was about 0.05 . Even in this case, the estimated total uncertainty is only $3 \%$ of the mean value. This value includes a $2 \%$ contribution for unburned hydrocarbons. For heptane, there was little smoke production, and the uncertainty was even less, with an estimated value of $2 \%$. 
There is an additional uncertainty component for the jet $\mathrm{A}$, the heptane blend, and the heptane/toluene mixture because the composition of the mixtures are not exactly known. In these cases, the uncertainty in $f$ was taken to be $1 \%$ of the estimated value $(f=0.84$, heptane, 0.913 , toluene, 0.88 , Jet fuel, 0.84 heptane blend, $0.87,40 \%$ toluene. $60 \%$ heptane blend by volume) The resulting expanded uncertainties were $2 \%$ of the mean for the heptane blend, and $2.5 \%$ for the jet fuel and the toluene/heptanes mixture. As above, the expanded uncertainty was estimated by combining in quadrature the total uncertainty with the uncertainty of the mean from repeat measurements, and then multiplying by a coverage factor of 2 . Finally, the total uncertainty for mass concentration was computed based on Eq. 6. The major individual uncertainties and the total relative standard uncertainty is presented in Table 3 .

\begin{tabular}{|l|c|c|}
\hline Table 2. Major Contributors to the Uncertainty in the Smoke Yield \\
\hline Variable & Typical Value & $\begin{array}{c}\text { Relative standard } \\
\text { uncertainty }\end{array}$ \\
\hline Mass of smoke & $1.945 \mathrm{mg}$ & 0.044 \\
\hline Volume fraction of $\mathrm{CO}_{2}$ & 0.0050 & 0.030 \\
\hline Moles of gas sampled & 0.373 moles & 0.036 \\
\hline Smoke yield & 0.076 & $\mathbf{0 . 0 6 4}$ \\
\hline
\end{tabular}

* This value, the relative total standard uncertainty, is computed as the root-sum-squares of the three individual values of uncertainty.

\begin{tabular}{|l|c|c|}
\hline Table 3. Major Contributors to the Uncertainty in the Mass Concentration. \\
\hline Variable & Typical Value & $\begin{array}{c}\text { Relative standard } \\
\text { uncertainty }\end{array}$ \\
\hline mass on the filter & $1.5 \mathrm{mg}$ & 0.021 \\
\hline mass on cloth & $0.35 \mathrm{mg}$ & 0.04 \\
\hline cleaning efficiency correction factor & 1.27 & 0.173 \\
\hline mass on tubing wall & $0.445 \mathrm{mg}$ & 0.178 \\
\hline mass of smoke & $1.945 \mathrm{mg}$ & 0.044 \\
\hline volume of smoke sampled & $0.00816 \mathrm{~m}^{3}$ & 0.040 \\
\hline mass concentration of smoke & $0.238 \mathrm{~g} / \mathrm{m}^{3}$ & $\mathbf{0 . 0 5 9}$ \\
\hline $\begin{array}{l}* \\
\text { This value, the relative total standard uncertainty, is computed as the root-sum-squares } \\
\text { of the uncertainties in the mass of smoke and the volume. }\end{array}$ \\
\hline
\end{tabular}

\section{Results and Discussion}

\subsection{Heat Release Rate}

Table 4 summarizes the heat release rate measurement results. The Table includes the mass flow of fuel ( $\dot{m})$, the idealized $\dot{Q}$, the mean measured $\dot{Q}$, the combustion efficiency, and the expanded uncertainties for each of these parameters. The mass flow of fuel was the product of the measured volumetric fuel flow and the fuel density listed in Table 1 . The idealized value of $\dot{Q}$ was the product of $\dot{m}$ and $\mathrm{H}_{\mathrm{c}}$, which were taken from Table 1 . The expanded uncertainty was computed with a coverage factor, $\mathrm{k}=2$, which defines an interval estimated to have a level of confidence of $95 \%$ and represents two 
times the standard deviation, $\sigma$, of the uncertainty. Based on measurement reproducibility, the relative expanded uncertainty of the mean fuel flow measurement was taken as $1 \%$ for all tests. The relative expanded uncertainty of the mean heat release measurement was typically 5\% for all tests, except for the jet fuel, which has an uncertainty of approximately $7 \%$, due to a particularly large uncertainty in the value of $\mathrm{H}_{\mathrm{c}} / \mathrm{r}_{\mathrm{o}}$ (see Table 1). The relative expanded uncertainty in the idealized heat release rate is lowest for the experiments using $\mathrm{n}$-heptane, where $\mathrm{H}_{\mathrm{c}}$ is well established.

The combustion efficiency, $\chi_{\mathrm{a}}$, as defined in Eq. 2 is shown in Table 4 for each of the tests. There is no significant difference between the measured value of $\chi_{\mathrm{a}}$ for the same fuel types over the heat release rates considered here. By definition, $\chi_{a} \leq 1$. Values of $\chi_{a}$ greater than one are not physical, but are indicative of measurement uncertainty. The value of $\chi_{\mathrm{a}}$ reported here was based on Eq. 2 . The uncertainty in $\chi_{\mathrm{a}}$ was dominated by uncertainty in the measured $\dot{Q}$.

Table 4. The measured fuel flow, $\dot{m} \cdot \mathrm{H}_{\mathrm{c}}$, the mean measured $\dot{Q}$, the combustion efficiency $\left(\chi_{\mathrm{a}}\right)$ and uncertainties (with a coverage factor of two).

\begin{tabular}{|l|l|c|c|c|c|}
\hline Test \# & Fuel & $\begin{array}{c}\text { Flow } \\
(\mathrm{L} / \mathrm{min})\end{array}$ & $\begin{array}{c}\dot{m} \cdot \mathrm{H}_{\mathrm{c}} \\
(\mathrm{MW})\end{array}$ & $\begin{array}{c}\dot{Q} \text { (meas) } \\
(\mathrm{MW})\end{array}$ & $\chi_{\mathrm{a}}$ \\
\hline 1 & Jet A & $3.26 \pm 0.03$ & $1.89 \pm 0.09$ & $1.56 \pm 0.11$ & $0.83 \pm 0.12$ \\
\hline 2 & Jet A & $5.02 \pm 0.05$ & $2.91 \pm 0.15$ & $2.66 \pm 0.19$ & $0.91 \pm 0.14$ \\
\hline 3 & Jet A & $3.26 \pm 0.03$ & $1.89 \pm 0.09$ & $1.77 \pm 0.12$ & $0.93 \pm 0.14$ \\
\hline 4 & Jet A & $5.02 \pm 0.05$ & $2.91 \pm 0.15$ & $2.72 \pm 0.19$ & $0.93 \pm 0.14$ \\
\hline 5 & Jet A & $3.26 \pm 0.03$ & $1.89 \pm 0.09$ & $1.78 \pm 0.12$ & $0.94 \pm 0.14$ \\
\hline 6 & Jet A & $5.02 \pm 0.05$ & $2.91 \pm 0.15$ & $2.71 \pm 0.19$ & $0.93 \pm 0.14$ \\
\hline 7 & Toluene & $3.01 \pm 0.03$ & $1.80 \pm 0.08$ & $1.37 \pm 0.07$ & $0.76 \pm 0.10$ \\
\hline 8 & Toluene & $4.77 \pm 0.05$ & $2.85 \pm 0.14$ & $2.10 \pm 0.10$ & $0.74 \pm 0.10$ \\
\hline 9 & heptanes & $2.79 \pm 0.03$ & $1.42 \pm 0.07$ & $1.51 \pm 0.08$ & $1.06 \pm 0.15^{2}$ \\
\hline 10 & heptanes & $4.55 \pm 0.05$ & $2.32 \pm 0.12$ & $2.24 \pm 0.11$ & $0.97 \pm 0.13$ \\
\hline 11 & n-heptane & $2.79 \pm 0.03$ & $1.42 \pm 0.02$ & $1.58 \pm 0.08$ & $1.11 \pm 0.12^{2}$ \\
\hline 12 & n-heptane & $4.55 \pm 0.05$ & $2.32 \pm 0.03$ & $2.35 \pm 0.12$ & $1.01 \pm 0.10$ \\
\hline 13 & Mixture & $3.08 \pm 0.03$ & $1.92 \pm 0.08$ & $1.40 \pm 0.07$ & $0.73 \pm 0.13$ \\
\hline 14 & Mixture & $5.01 \pm 0.05$ & $3.13 \pm 0.14$ & $2.08 \pm 0.10$ & $0.66 \pm 0.12$ \\
\hline $1 . t h e$ & fixture was & composed & $60 \%$ hept & \\
\hline
\end{tabular}

1. the fuel mixture was composed of $60 \%$ heptanes $+40 \%$ toluene by mass. 2. By definition, $\chi_{\mathrm{a}} \leq 1 . \chi_{\mathrm{a}}$ is based on Eq. 2 , in which the uncertainty in $\chi_{\mathrm{a}}$ is dominated by uncertainty in the measured $\dot{Q}$. 


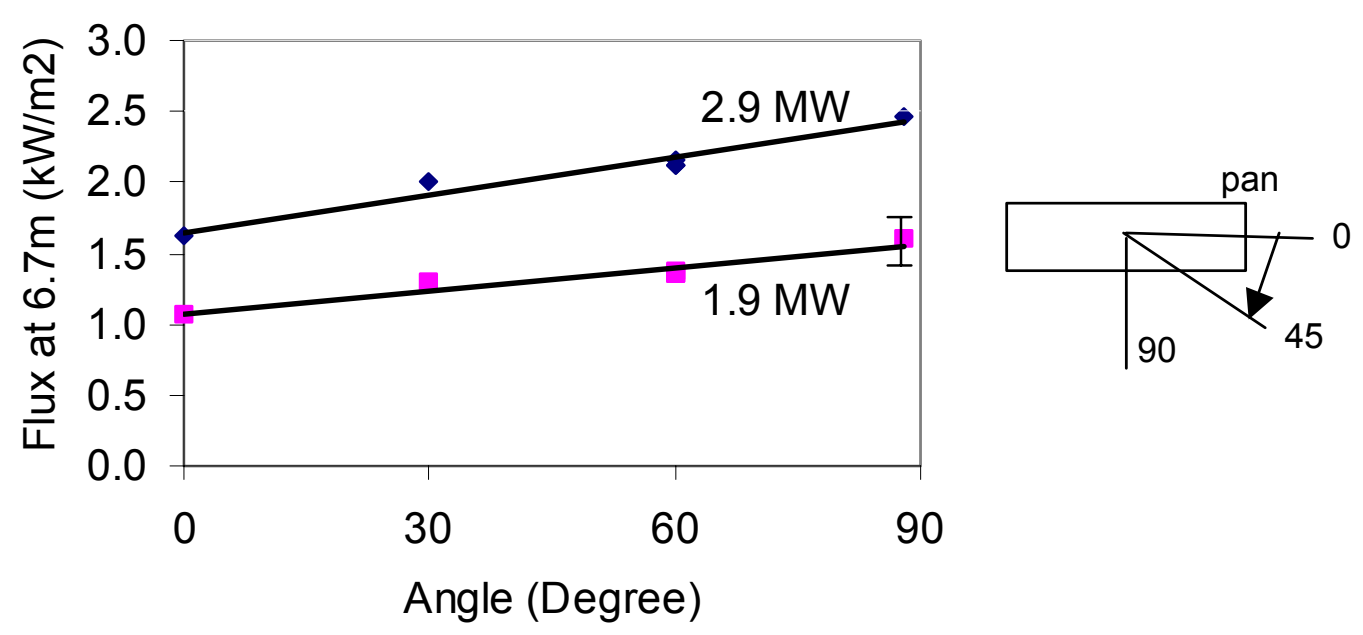

Figure 2. Radiative heat flux measured at a distance of $6.7 \mathrm{~m}$ from the fire as a function of angle about the center of the rectangular burner (see schematic on right) for $1.9 \mathrm{MW}$ and 2.9 MW Jet A spray fires.

\subsection{Radiative Fraction}

An example of the radiative heat flux measurement results are presented in Fig. 2, which shows the flux as a function of angle about the rectangular spray burner for $2 \mathrm{MW}$ and $3 \mathrm{MW}$ Jet A fires. The flux varied as a function of angle in a fairly linear fashion. This was consistently observed for all of the fuel types and fire sizes.

Because of space limitations during the measurements, the burner was positioned within $5 \mathrm{~m}$ of a wall. A supplementary series of measurements was conducted to determine the impact of reflection from the wall on the heat flux measurements. The value of $\chi_{\mathrm{r}}$ was determined with and without the wall present. The results showed that wall reflection accounted for approximately $8 \%$ of the radiative heat flux. The radiative fraction results reported here were corrected for this effect.

The point source assumption for radiative flux was tested by comparing the values of the product of $\dot{q}^{\prime \prime}$ and the square of the distance to the center of the fire (R) with the heat flux gauge positioned at various values of $\mathrm{R}$ for $\theta=0^{\circ}$ and $\theta=90^{\circ}$ (see Fig. 1). The measurements showed that there was less than $2 \%$ difference in the value of the product of $\dot{q}^{\prime \prime}$ and $\mathrm{R}^{2}$ derived from radiative flux measurements at $6 \mathrm{~m}$ and $13 \mathrm{~m}$.

Several factors contributed to the estimated measurement uncertainty for $\chi_{\mathrm{r}}$, including measurement variance and the uncertainty associated with calibration, which was taken as approximately $5 \%$ (with a coverage factor of two). The uncertainty in the correction factor for wall reflection (for fuels other than heptane) also contributed to the estimated uncertainty.

Table 5 shows that there was no significant difference in the radiative fraction for the fire sizes tested here (refer to Table 4 for fire heat release rate). For the same fuel type, the 
Table 5. The measured radiative fraction $\left(\chi_{\mathrm{r}}\right)$ and uncertainties (with a coverage factor of two).

\begin{tabular}{|l|c|c|}
\hline Test $\#$ & Fuel & $\chi_{\mathrm{r}}$ \\
\hline 3 & Jet A & $0.40 \pm 0.08$ \\
\hline 4 & Jet A & $0.40 \pm 0.08$ \\
\hline 7 & Toluene & $0.43 \pm 0.08$ \\
\hline 9 & Toluene & $0.37 \pm 0.08$ \\
\hline 10 & Heptanes & $0.44 \pm 0.06$ \\
\hline 11 & Heptanes & $0.47 \pm 0.06$ \\
\hline 12 & n-heptane & $0.45 \pm 0.08$ \\
\hline 13 & n-heptane & $0.45 \pm 0.08$ \\
\hline 14 & mixture $*$ & $0.35 \pm 0.08$ \\
\hline$*$ the fuel mixture was composed of $60 \%$ heptanes and $40 \%$ toluene by \\
mass. & mixture * & $0.34 \pm 0.08$ \\
\hline
\end{tabular}

yields of soot, $\mathrm{CO}$, and $\mathrm{CO}_{2}$ for the various tests showed little difference. Table 6 shows the mean measured values for the yields of soot, $\mathrm{CO}$, and $\mathrm{CO}_{2}$ for the different fuel types.

Table 6 also shows the averaged measurement results as a function of fuel type for the combustion efficiency and the radiative heat loss fraction. The radiative heat loss fraction for the spray fire studied here was larger than a pool fire with a similar $\dot{Q}$ burning the same fuel. The value of $\chi_{\mathrm{r}}$ for a heptane or toluene pool fire has been reported to be 0.35 and 0.36, respectively [Hamins et al., 1996]. The larger value of the radiative fraction for the spray flames is attributed to differences in the structure of these fires, as fuel atomization plays a role in the effective fuel burning surface, the rate of fuel evaporation, and fuel burning.

\begin{tabular}{|c|c|c|c|c|c|}
\hline Fuel & $\begin{array}{c}\text { Combustion } \\
\text { efficiency }\end{array}$ & $\begin{array}{l}\text { Radiative } \\
\text { fraction }\end{array}$ & Soot yield & $\mathrm{CO}$ yield & $\mathrm{CO}_{2}$ yield \\
\hline Heptanes & $1.01 \pm 0.14$ & $0.45 \pm 0.06$ & $0.0149 \pm .0019$ & $<0.008$ & $3.03 \pm 0.12$ \\
\hline Toluene & $0.75 \pm 0.10$ & $0.40 \pm 0.08$ & $0.195 \pm 0.052$ & $0.070 \pm 0.017$ & $2.52 \pm 0.22$ \\
\hline n-heptane & $1.06 \pm 0.14^{2}$ & $0.45 \pm 0.08$ & $0.0108 \pm 0.0014$ & $<0.008$ & $3.04 \pm 0.12$ \\
\hline Jet A & $0.93 \pm 0.14$ & $0.40 \pm 0.08$ & $0.097 \pm 0.016$ & $0.030 \pm 0.009$ & $2.82 \pm 0.15$ \\
\hline $\begin{array}{l}\text { Heptanes/ } \\
\text { Toluene }^{1}\end{array}$ & $0.70 \pm 0.13$ & $0.35 \pm 0.08$ & $0.114 \pm 0.022$ & $0.042 \pm 0.016$ & $2.70 \pm 0.15$ \\
\hline \multicolumn{6}{|c|}{$\begin{array}{l}\text { 1. the fuel mixture was composed of } 60 \% \text { heptanes and } 40 \% \text { toluene by mass. } \\
\text { 2. By definition, } \chi_{\mathrm{a}} \leq 1 . \chi_{\mathrm{a}} \text { is based on Eq. } 2 \text {, in which uncertainty in } \chi_{\mathrm{a}} \text { is dominated by } \\
\text { uncertainty in the measured } \dot{Q} \text {. }\end{array}$} \\
\hline
\end{tabular}




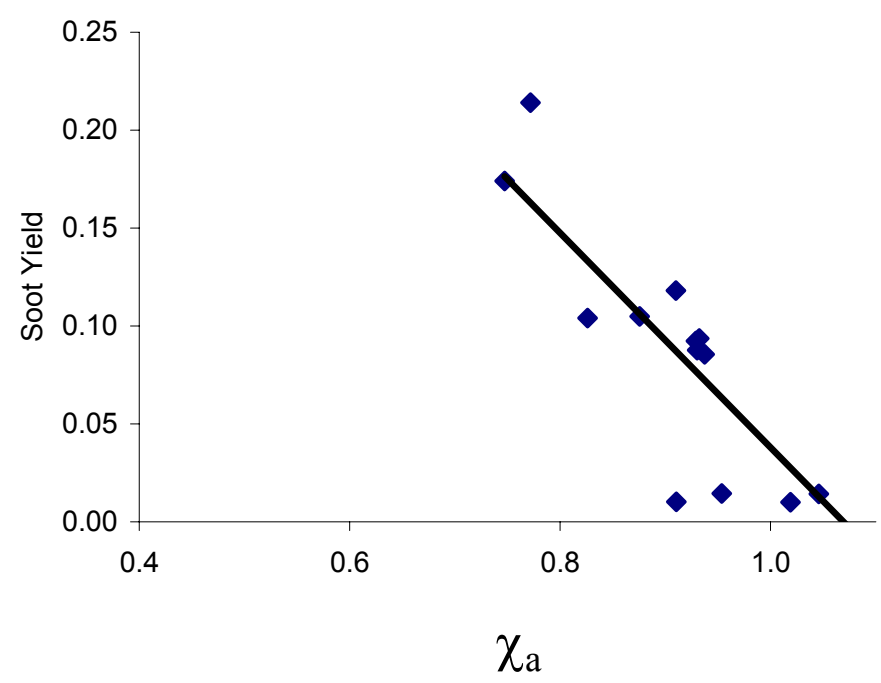

Figure 3. The soot yield as a function of the combustion efficiency for the $1 \mathrm{MW}$ to $3 \mathrm{MW}$ fires burning the fuels considered in this study. Uncertainties are listed in Table 6.

Table 6 also shows the combustion efficiency, $\chi_{\mathrm{a}}$, for the various fuels studied here. As expected, the combustion efficiency is lowest for toluene, which is a very smoky fuel. Tewarson [1986] found similarly low values of the combustion efficiency for toluene.

The relationship between the measured soot yield and the combustion efficiency is shown in Fig. 3. As expected, as the soot yield increased, the combustion efficiency decreased. This is consistent with the results of Tewarson [1986], who measured increases in soot yield and decreased combustion efficiency as a function of smoke point height in smallscale experiments. The figure includes a best fit line to the data, which does not adequately represent the data, but does capture its trend.

\section{Conclusions}

The magnitude of the uncertainty associated with the determination of $\chi_{a}$ is relatively large, due to the inherently large uncertainty of the heat release rate measurement.

Significant innovation in the measurement approach is needed to reduce the $\chi_{\mathrm{a}}$ uncertainty. One possible approach may be to measure the detailed combustion products and consider changes in the heats of formation of the reactant and product yields, relative to complete combustion. At a minimum, such an approach would assure that $\chi_{\mathrm{a}}$ was less than unity.

\section{Acknowledgements}

The authors are grateful to Edward Hnetovsky, Lauren DeLauter, and Mike Selepak, for providing expert technical assistance, and to Dr. Matthew Bundy, Dr. Rodney Bryant, Mr. Rik Johnsson, and Ms. Michelle Donnally for very helpful discussions. 


\section{References}

Bryant, R., Ohlemiller, T., Johnsson, E., Hamins, A., Grove, B., Guthrie, W.F., Maringhides, A., and Mulholland, G., The NIST 3 Megawatt Quantitative Heat Release Rate Facility Procedures and Guidance, NIST Special Publication 1007, National Institute of Standards and Technology. Gaithersburg, MD, December 2003.

Bryant, R., Ohlemiller, T., Johnsson, E., Hamins, A., Grove, B., Guthrie, W.F., Maringhides, A., and Mulholland, G., The NIST 3 Megawatt Quantitative Heat Release Rate Facility description and Procedures, NISTIR 7052, National Institute of Standards and Technology, Gaithersburg, MD, September 2004.

Hamins, A., Kashiwagi, T., and Buch, R., in Fire Resistance of Industrial Fluids (Eds.: Totten and Reichel), ASTM STP 1284, 1996.

Hamins, A., Maranghides, A., Yang, J., Donnelly, M., Mulholland, G., Ohlemiller, T., and Johnsson, E., Report of Test on Experimental for the International Fire Model Benchmarking and Validation Exercise \#3, NIST Special Publication 1013, National Institute of Standards and Technology. Gaithersburg, MD, November 2003.

Galbraith Labs, Report of Test Results, March 2003.

Leonard, S., Mulholland, G.W., Puri, R., and Santoro, R.J., Combust. Flame, 98: 20-34 (1994).

Modak, A.T., Factory Mutial Research Corp., Norwood, Ma., Technical Report Serial No. 22361-5, RC-B-67 (1976).

Modak, A.T., Combust. Flame, 29: 177-192 (1977).

Tewarson, A., Prediction of Fire Properties of Materials, Part 1. Aliphatic and Aromatic Hydrocarbons and Related Polymers, NIST Report \#NBS-GCR-86-521, Dec. 1986. 